\title{
Satisfaction Evaluation of the Effectiveness of the Two Models of Specialty-Oriented Career Planning Course
}

\author{
Huiling Peng ${ }^{1}$, Yueh-Hsiang $\operatorname{Lin}^{1} \&$ Chun-Ju Lin ${ }^{2}$ \\ ${ }^{1}$ Department of Finance, National Taipei University of Business, Taipei, Taiwan \\ ${ }^{2}$ Office of Research \& Development, National Taipei University of Business, Taipei, Taiwan \\ Correspondence: Huiling Peng, 2F, No. 8, Alley 68, Lane 41, Keelung Road, Section 4, Taipei, 10673, Taiwan. \\ E-mail: hxp7@ntub.edu.tw
}

Received: July 8, 2017

Accepted: July 19, 2017

Online Published: August 7, 2017

doi:10.5539/ijps.v9n3p51

URL: http://doi.org/10.5539/ijps.v9n3p51

\begin{abstract}
This research is a two-semester experimental program that uses Freshman's "Finance Career Planning" of the undergraduate program of the finance department of the National Taipei University of Business (NTUB) as the experimental curriculum. This research explores and analyzes two models of "Specialty-oriented career planning course" to see if there is a difference in students' course satisfaction. The features of the second model include specialty-oriented lectures by finance alumni and assignments requiring the interviewing of upperclassmen, in addition to studying career counseling theory and specialty-topic content sharing. This research finds that there is a significant difference in students' course satisfaction within the two models of "specialty-oriented career planning course", wherein the second model is considered better than the first model, and the average scores of the five indicators of students' course satisfaction have all reached a significant level (the richness of course content, the clarity of lecturer's conveyance, the level of personal learning acquirement, the relevancy of course content to the topic, the design of course process and activities). This research proposes the following recommendations, in accordance with the research findings, that institutions of higher education should offer practical and feasible specialty-oriented career planning courses.
\end{abstract}

Keywords: career counseling, specialty-oriented career planning, career decision making

\section{Introduction}

The inspiration for this research originated from the two-semester experimental program "Career Education Promotional Model", organized by NTUB and Taipei Youth Salon (TYS), that uses Freshman's "Finance Career Planning" of the undergraduate program of the finance department of NTUB as the experimental curriculum (Lin \& Peng, 2015; Lin C., Lin Y., \& Peng, 2016) to compare the teaching satisfaction of the two different course design models. TYS was founded in 2013. The purpose of its service is to guide youths in finding their own career direction and to assist in the sustainable development of their careers. Since its inception, there have been many programs developed by TYS and NTUB's R\&D department to service students, such as, implementing aptitude tests for all freshmen. Since its restructuring in 2014, NTUB has set its development vision to become the best business college in Taiwan, with the core educational goal of cultivating professional business talents. So far, of the seven departments of NTUB, only the finance department offers a career planning course, which started in 1996, and is the first department to offer the Freshman's specialty-oriented "finance career planning" course, since the 2014 NTUB restructuring.

\subsection{Background}

The issue of talent shortage in Taiwan is now very serious. Institutions of higher education should pay more attention to implementing specialty-oriented career planning courses in each department. In the "2016 Global Talent Shortage Survey", conducted by Manpower Group, in which 42,000 employers, covering 43 nations and regions, including 1,005 Taiwanese employers, were surveyed. The results of which show, that as high as $73 \%$ of employers in Taiwan are facing the difficulty of finding talents, which ranks the second highest in the world. Compared to the results of last year (2015), there is an increase of 16 percentage points for Taiwan, which is the highest increase since joining the survey in 2006. "Of the top ten positions of talent shortage listed for Taiwan, sales representatives, engineers and technicians are still ranked as the top 3. Other positions, such as R\&D staff 
and management staff, are still in the top rankings, showing that the talent shortage issues in Taiwan have not significantly improved. Since 2009, the phenomenon of global talent shortage worsens every year. The talent shortage challenge in Taiwan has expanded drastically in the last two years, mainly due to rapid changes in the industrial trends that offset the usual pace of talent cultivation and the speed of supply". Additionally, more than half of the employers in Taiwan said that the reasons for talent shortage are: (1) lack of available applicants or no applicants (53\%); (2) other reasons include: lack of experience (10\%); corporate factors $(10 \%)$; lack of hard skills required in the workplace $(10 \%)$. Every college department should help college students with professional career planning early in their studies to improve their professional employability and the specialty employment rate at the time of graduation.

After the expansion of higher education in Taiwan, the problem of the "mismatch between education and work", especially during the transition from school to work, increased. This requires closing the gap that connects "school taught" and "student learned" with the employment market of the future, in order to achieve the educational goal of nurturing professional talent that can apply what is learned. The "mismatch between education and work" refers to that phenomenon where fresh graduates cannot apply their freshly learned knowledge and skills at the workplace. The analysis and report proposed by Weng and Chang (2011) indicates that $55 \%$ of employed young people in 2010 believed that they can apply what they learned at work; while the remainder of the people maintained a reserved attitude about the relationship between what they learned and the jobs they currently have. Twenty percent of this group, young males between the age of 25 and 26, are NEET (Not in Employment, Education or Training), who are neither studying nor working, but hanging in a state of indecision. The report also mentioned that "from the perspective of applying what was learned, only $9 \%$ of technical college graduates believe that they are applying what they learned, a number which is lower than the $16 \%$ of people who graduated from general colleges, and even lower than the $13 \%$ of junior college graduates. Such a result is very different from the expectations of the general public, showing that current curriculum design and the teaching content of technical colleges are in need of re-examination”. They made a special emphasis on the fact that, after the expansion of higher education, technical college graduates are no better off than general college graduates in applying what they learned. Now, with the help of various institutional adjustment measures, we hope to mitigate the mismatch between education and work, and in further assisting young people in smoothly completing the transition from school to work.

The goal of National Taipei University of Business (NTUB, hereafter) is to cultivate excellent business talents. The mission of NTUB is to: (1) provide the best business and design education available to help stimulate learning and innovation; and (2) cultivate talents with professional skills and integrity for social responsibility. The position of NTUB: in the short-term, is to be a university that teaches practical business management; in mid-range development, featuring digital innovation with the cooperation of industry, government and academia; in the long-term, is to be a university of applied business management innovation and digital innovation (Lin, 2016). The goal of the Finance Department of NTUB is to cultivate first-rate finance professional talents. The school features two education programs (finance technology program and finance innovation program) and three curriculum modules (finance insurance module, finance management module and financial investment strategy module). Finance Insurance Module: cultivates professional talents needed in the banking industry and the insurance industry; Finance Management Module: focuses on cultivating corporate finance/accounting management professionals; Financial Investment Strategy Module: focuses on cultivating professionals in the operation of financial markets and financial instruments, and professionals skilled in the securities and futures related industries. The financial career planning course and ethics education course, offered by the Finance Department, are both important auxiliary courses for professional training (Lin, 2016). The goal of the financial career planning course is to cultivate students' soft power to use in their employment: (1) help students to explore themselves, to be aware of personal potential, and to cultivate independent thinking and creativity; (2) help students to understand the career paths and workplaces in the financial industry, clarify future career goals and to cultivate soft power for the workplace, so as to become experts in the financial field; (3) help students to cultivate the right values, form good ethics and gain internal motivation; and (4) help students to enhance positive personal characteristics and thus be welcomed by the workplace: easy to get along with, respectful, responsible, fair, trustworthy, caring and civically responsible. To become a leader in the workplace, one needs to learn the good characteristics of being led. 


\subsection{Career Counseling and Career Decision Making}

The emphases of Career education are on: (1) developing career decision-making ability; (2) developing self-concept; (3) paying attention to life style, values and recreation; (4) stressing on freedom of choice and bearing responsibility; (5) paying attention to individual differences; and (6) responding to external changes; career learning is responses learning (Jin, 2011). According to the studies on domestic and international career education for higher education, college students in general are in need of career counseling. The research results of, "The Career Development of Chinese College Students in Taiwan", conducted by Jin, Lin and Tien (1989), show that the current status of career decision-making for a majority of college students, is "exploratory and undecided". A great number of college seniors feel that their majors are not what they originally thought they would be, but they have gradually developed a liking for the major as they approach graduation. Career counseling intervention strategies (intervention strategies that use four cognitive information process programs: Meaning-Enhancement for Repertory Grid, Card Sort, Computer-Assisted Vocation Information System, and Balance Sheet) may enhance students' career constructs and improve the self-efficacy of career decisions (Jin \& Sheu, 2010). To nurture the ability of choosing a profession of undecided college students, these factors relating to making a career choice should still be considered: self-concept, personality traits, career interests, career self-efficacy, values, career beliefs, spirituality and others (Lepper, 2016; Steele, 2016). In Huang's research (2016), "The study on the relationships among differentiation of self, career coping strategies and career decisions of college students", the findings show that: college students' gender, self-differentiation/self-concept and four career-response strategies are predictive of career orientation. The research of Mao, Hsu, and Fang (2016) finds that only accurate self-evaluation has a significant mediating effect on both variables, "parental emotional support" and "career indecision due to unreliable information". Additionally, many domestic and foreign studies relating to self-concept and career choices propose that a good development in self-concept is helpful in improving the quality of a career decision.

Career education may assist students with their career decisions. Fearon, Nachmias, McLaughlin, and Jackson (2016) mention in "Personal values, social capital, and higher education student career decidedness" that from an employability perspective, the ultimate responsibility for becoming a "protean graduate" rests with each student, whilst the obligation of college education staff is to effectively facilitate and nurture all possible personal growth and skills development opportunities. In Social Cognitive Career Theory, "Contextual support" type (for example: the number of times parents support and receive career counseling) will affect persistence. "Career Self-Efficacy" and "Career Decidedness" play mediating roles in the relationship between "contextual support" and "persistence" (Restubog, Florentino, \& Garcia, 2010). In addition, Ginevra, Pallini, Vecchio, and Nota (2016) emphasize the importance of supporting adolescents with their career adaptability, hope, optimism and future directions. Their study shows that "positive attitude towards the future", "the future direction" and "career decidedness" can indirectly predict career adaptability. The research of Shih (2010) indicates that college students' self-concept significantly affects the quality of career decisions. Poor development of self-concept, and lack of awareness and understanding about self and external working environment may cause a panic in students when choosing their future professions. Liang (2016) compiled three scales of career orientation based on college students' work values, personal and environmental adaptability, and verifies the reliability and validity of these scales.

Career choices are related to physical and mental health; physical and mental health will also affect an individual's career planning and future career development (Peng \& Huang, 2007). Brown and Lent (2016) discuss agency, equity, and well-being from the perspective of vocational psychology. They review and organize vocational psychology literature published between 2007 and 2014 into three overarching themes: promoting (a) agency in career development, (b) equity in the work force, and (c) well-being in work and educational settings. They review research on hedonic (work, educational, and life satisfaction) and eudaemonic (career calling, meaning, engagement, and commitment) variables, with the goal of understanding how well-being might be promoted at school and at work. The research of Arnold (1989) finds that the "decidedness of career choice" and "well-being" are significantly correlated; it is particularly obvious when sustaining a career choice through graduation that leads to high levels of well-being. Chason (2011) researches and proves that there is an inverse relationship between career decidedness, satisfaction with choice, and negative career thoughts. It is necessary to fully explore the impact of negative thinking, because it interferes with an individual's effectiveness when making career decisions. The three most common forms of career counseling are: (1) individual counseling: it has existed since the beginning of the career guidance movement and it is the most popular assistance method; (2) career group counseling, which emerged in the 1950s; (3) the rise of the career planning course began in the 1930s, and gradually developed into career-oriented and decision-based courses (Davis \& Horne, 1986). 
An effective career-counseling program can emphasize the preparation of field experience and can design activities for subsequent experience. In "Career construction as a way of resolving career indecision", written by Maree (2016), the Career Construction Interview (CCI) was used to collect qualitative data, and Savickas's eight-step strategy was used to complete the participant's life portrait. The results suggest that the interventions helped the participants clarify and resolve career indecision. The findings in the research of Lam (2016) "Effects of a career course on students' career decision-making self-efficacy, indecision and difficulties" show that participants in the experimental group experienced increased career decision-making self-efficacy and reduced career indecision tendencies upon completion of the course. These participants also showed an overall decrease in career decision-making difficulties. The study conducted by Shelby (2010) on the impact of a standardized cognitive information processing intervention on the career decision state of at-risk youth finds that many participants like these activities and they are satisfied with the impact of education on setting career goals. Van Tuijl, C. and Van der Molen (2016) point out that the learning choices and career decisions made by young adults are traceable to their childhood. Their paper reviewed three inter-related factors: knowledge, affective value, and ability beliefs and self-efficacy building. The deep-rooted negative and stereotypical affective values associated with science and engineering learning choices and careers, especially among parents and teachers, must be overturned. As for the ability beliefs, the focus should be placed on the growth of children's/students' intrinsic beliefs. Lent, Ezeofor, Morrison, Penn and Ireland (2016) also mention that decisional self-efficacy factor and the established measure of career decision self-efficacy are strongly correlated, and they generate theoretic consistency in relation with the measures of outcome expectations, social support, conscientiousness, exploration goals, prior engagement in career exploration, decisional anxiety, and level of career decidedness. Peña-Calvo, Inda-Caro, Rodríguez-Menéndez, and Fernández-García (2016) stress that Social Cognitive Career Theory (SCCT) states that career interest is influenced by four cognitive variables: self-efficacy beliefs, outcome expectations, interests, and goals. Other variables, such as social supports, peers and family and teaching staff support, also produce important impacts.

\subsection{The Importance of Specialty-Oriented Career Counseling}

Specialty-Oriented Career Counseling is very important for the development of technical and vocational education, since it can enhance college students' self-exploration of their specialties and growth. Technical and vocational education systems should pay more attention to freshman's "Specialty-Oriented Career Planning Courses" and career counseling, and encourage college students to deeply explore their innate orientations and interests and social workplace trends, with the help of freshman career planning course/practical intern study programs, and diverse extracurricular life experience, thereby finding guidance in their career planning for their specialty development in the future (Peng, 2015b, 2016). The importance of specialty-oriented career planning courses: (1) Stimulate students' learning specialty motivation; (2) Help with early planning on specialty-oriented careers; (3) Promote future professional specialty employability/competitiveness (Peng, 2015b). Institutions of higher education in Taiwan should pay more attention to "Specialty-Oriented Career Counseling", because many freshmen are confronted with specialty indecision, rather than undecided confusion, in the realm of career choices. For example: how can a college freshman, majoring in finance, know if he will be good at banking, insurance, security or other financial specialty. The "Specialty-Oriented Career Counseling", as referred to in this research, is different from general college freshman orientation. This paper stresses that freshmen of vocational and technical education should pay attention to the "Specialty-oriented" career counseling offered by their own department. The career counseling segment of higher education in Taiwan needs to enhance students' employment competitiveness and increase students ambition for their professional specialty, in addition to placing focus and emphasis on specialty-oriented counseling, thereby improving students' specialty employability.

In 1985, Savicks and other scholars found that, in choosing a specialty, medical school students experience specialty indecision. To study this problem, they developed a specialty-oriented questionnaire to "measure specialty indecision among career-decided students". Their findings show that the "specialty indecision scale" is helpful in diagnosing specialty indecision, and then proceeding on to offer career counseling to medical students with specialty indecision (Savickas, Alexander, Jonas, \& Wolf, 1986; Savickas, Alexander, Osipow, \& Wolf, 1985). Borges, Manuel, Duffy, Fedyna, and Jones (2009) state that students can instinctively construct and internalize educational experiences relating to their career development. Understanding this process is very important to the work of career counseling. Their paper investigates how exploring behaviors can help first-year medical students in choosing a specialty within a community-based field experience course. The study compares the influences on choosing a specialty on students entering person-oriented specialties and students entering technique-oriented specialties. The study states: medical educators should be aware of how medical school-based 
experiences and interactions (such as: educators, courses, services) affect students' specialty choices and decisions, which shows that differences in influences on specialty decision-making exist. This research may be helpful to medical educators and advisors who work with students on specialty decision-making. Additionally, Hadadgar, Yousefi, Sabouri, and Richard (2009) state that using a web-based career counseling system, with an introduction by a counselor, may help medical students in the decision making process of choosing a specialty.

The definition of career indecision is: having difficulties making career decisions. The status of career development for each person is different. Some students encounter various issues of uncertainty, leading to the inability to make a career choice. Therefore, when offering career counseling, the identification and analysis of career indecision is a very important step. There can be a wide range of causes for career indecision. In the "Manual for the Specialty Indecision Scale", complied by Richard, Savickas, Early, Calli, Carissa, Englert, and Bono (2007), the score for six major career concerns (Readiness, Information, Identity, Barriers, Indecisiveness, and Self-Doubt) are used to identify the causes for specialty indecision of medical students. They further recommend that career counseling staff should reference and focus on the highest scoring items when helping specialty-indecision students overcome these difficulties. The importance of specialty orientation is not limited to the study of medical students' specialty indecision (Borges, 2007; Sajjad, Khan, \& Qayyum, 2016). Zachar and Leong (1997) point out that specific preferences are more predictive of specialty interests. They offer these observations on the impact of counseling in their findings: In terms of both theoretical orientations and vocational personality, counseling and clinical doctoral students differ from experimental doctoral students. The counseling and clinical doctoral students do not differ on theoretical orientations, but do differ on vocational personality, with counseling doctoral students being more socially oriented than clinical doctoral students.

College career education often focuses on the cultivation of students' employability; while, professional specialty strength is actually the most important employability factor, that is, competitiveness. There are two aspects of employability: core employability, and specialty and technical ability. Core employability refers to a wide range of adaptabilities and competencies for various work requirements; while, specialty and technical ability refers to the skills that apply to specific industries and jobs. In addition to the cultivation of specialty competence, the emphasis of higher education is to nurture core employability and to enhance workplace competitiveness for college students and strengthen their commitment to life-time learning! The talent cultivation in Europe and the U.S. focuses on living management in the preschool stage, environmental exploration in the primary school stage, searching for dreams in the secondary school stage, making career choices in the high school stage, and then cultivating practical skills in college education. In contrast, study and tests occupy the preschool to high school focus for the talent cultivation in Taiwan, and it's only in the college phase that living management, environmental exploration, finding dreams, career choices and the cultivation of practical skills come into focus, in addition to the study and tests paradigm. In the Action Research on Specialty-Oriented Counseling and the Construction of Alumni Career Information-Using the Finance Department of NTUB as an Example, Cui, Wang and Peng (2015) suggest: (1) Linking an "Alumni Career Information System" to a "Specialty-Oriented Career Counseling" program makes the blueprint of technical and vocational education clearer and more precise; (2) Continuous construction and updating of the "Alumni Career Information System" to reflect the development trends of the finance industry, so that "Specialty-Oriented Career Counseling" is always up-to-date; (3) Combining resources from the governments, schools and corporations in one fell swoop to help promote the "Alumni Career Information System". Connecting the communication channels between students and alumni enables current students to learn from the outstanding alumni.

\subsection{Role Model and Specialty-Oriented Career Counseling}

Role modeling should be the center of Specialty-Oriented Career Counseling, since it helps cultivate students' confidence in specialty-oriented choices, professional values, professional attitudes, in addition to offering students consultation, teaching, friendship, affirmation and acceptance; thereby, promoting students' learning motivation and career adaptation. The importance of role modeling on an individual's career development has been widely recognized in literature. In the "Role Model Influence on the Career Decidedness of College Students", Perrone, Zanardelli, Worthington, and Chartrand (2002) find that role-model supportiveness and role-model relationship quality contributed significantly to the career decidedness of participants. The research findings of Akbulut (2016) suggest that role models do not directly affect students' aspirations to major in Information Systems. However, role model programs affect students' academic choices indirectly through self-efficacy, outcome expectations, and interest factors. Association with role models may increase students' confidence in believing that they may perform well as Information System majors, and increase their positive expectations on the value rewards brought on by majoring in the said subject. Role models also increase 
students' interests in majoring in Information Systems and its career opportunities, and in turn raise students' yearning for majoring in Information Systems.

Mentorship and sponsorship are both very important to career development. Whether men or women, those with sponsorship are more likely to self-transcend, to get promotion opportunities and to ask for a raise, than those without sponsors (Sandberg, 2013). The mentoring relationship must be established on professionalism. Role models are to teach by example, and know where to place the effort: "We must decide what is important, and what is not important. Learn to be a perfectionist on what is important". Mentees must be able to make good use of the time, be open-minded, accept feedback and suggestions to enable a continuous relationship with role models or mentors. This friendship-like mentoring relationship is built on the basis of a professional relationship. Role models are very helpful to college students with specialty indecision, in that it helps in creating and promoting college students' specialty competitiveness, and subsequently in meeting the career requirements in the development of their specialties. One of the major strategies of specialty career development is to help students in finding the role models to learn from and in gaining the experience from what is similar to a mentoring relationship. Peng (2016) states that the establishment of an upper-classman or alumni system and then including members in the planning of teaching models may produce long-term effects in mentoring relationships. The mentoring relationship of upper-classman within a department may be defined as the relationship between more experienced people and less experienced people, within the realms of professional learning. The high operating quality of such a role-model mentoring relationship may make it the best way to help students in developing specialty career planning. She hopes that the course design of mentoring relationships with role modeling may enhance students' course-learning satisfaction; then, in turn, affect career effectiveness and career values.

\subsection{Research Motivation and Objectives}

After years of attending and observing many career-counseling lectures at NTUB, I believe that students can benefit in having more comprehensive information as offered by credit courses, if they are offered. Thus, NTUB co-organized a two-semester experimental program during the 2015-2016 school year, "Career Counseling Education Promotional Model" with TYS, using Freshman's "Finance Career Planning" of Finance Department of NTUB as the experimental curriculum. The purpose of this research is to explore, analyze and compare the two models of experimental courses to see if the two different models of instruction content of "specialty-oriented career planning course" produce different results in students' course satisfaction. The promotional effectiveness of this research is measured by tabulating participants' scores on five indicators in the satisfaction scale (the richness of course content, the clarity of lecturer's conveyance, the level of personal learning acquirement, the relevancy of course content to the topic, the design of course process and activities), which are supplemented with students' open responses, to indirectly obtain students' reactions in attitude and perception. Finally, concrete suggestions are offered in this study, specifically on the two models of "specialty-oriented career planning" courses, so that students may be able to decide on their specialty early and enhance the quality of their choices for specialty-oriented careers, thereby improving their "specialty employability" and "specialty employed rate".

\section{Method}

This research focuses on theoretically based analysis and practical course implementation design, and includes literature review and practical course operation. The "Satisfaction" questionnaire survey method with single-group posttest experimental design is adopted by this research, where satisfaction is the dependent variable with five subscales, independent variables are the two models, and control variables are the years of study. Research process: bi-direction progression of both theoretically based analysis and practical operation. In this study, the "Financial Career Planning Course Feedback Form" is used to verify the student's individual satisfaction assessment of the course, in addition to using the common teaching evaluation process used by schools for supplemental explanation. The Action Research method is used to invite the participation of industry alumni, full-time instructors and students, so that students may be able to identify their career orientation in the action of "specialty-oriented career counseling". The participants of this research in the elective "career planning" course are the first-year finance department students of a four year technical college, where 48 daytime students participated in the first model, and 56 first-year finance students were the research subjects in the second model. Meanwhile, participants have access to anonymous experience sharing. Interview files of the career development stories contributed by finance department alumni are compiled and published on the finance department career planning teaching website, Dreamer, (http://www.dreamerpengh.com/) for students who are interested in joining a financial specialty, as a reference. 
The statistical methods used in this study include the descriptive statistical analysis, the mean and standard deviation of the satisfaction variable of two different models to describe the students' satisfaction status concerning the two models of financial career planning courses. In addition, t-test is used to explore students' course satisfaction differences between the two models, and to see if the differences are significant. The indicators include: (1) the richness of course content; (2) the clarity of lecturer's conveyance; (3) the level of personal learning acquirement; (4) the relevancy of course content to the topic; (5) the design of course process and activities; and (6) overall satisfaction. The research is supplemented with an analysis of responses to the qualitative open questions of tracked samples.

The Specialty-Oriented Career Counseling referred to in this research is different from the orientation counseling of college freshmen; in which, the learning theory of the former is based on a career. In general, orientation counseling, also known as "Freshmen Training", adopts group counseling method, and offers students appropriate help in adapting to unfamiliar environment during a change in their living situation. The Orientation Service of the Freshmen Training in higher education is designed primarily for freshman students entering an unfamiliar environment. Its purpose is to assist new students, facing the challenge of unfamiliar environment, to adapt to college life. College Freshman Training is a one-time orientation counseling event. The one-semester career planning course, "Financial Career Planning", offered by the Finance Department, incorporates the concept of nurturing financial specialty talents in the curriculum of a "career planning" course. When students establish a learning process in this department it cultivates their ability to "apply what they have learned", and inspires them to engage with determination and passion in banking, insurance, security, financial administration, or other financial related industry. The two models of experimental courses are in different semesters. The research focus is the NTUB Financial Career Planning course that lasts 18 weeks per semester. The instruction focus of the first model is on the theory of career specialty planning; while, the second model focuses on spirituality - conveyance of spirituality, with alumni speeches and learning advisor assignments as the course methods. The features of the second model include specialty-oriented lectures by finance alumni and assignments of interviewing senior students, in addition to TYS sharing career counseling theory and specialty-topic contents.

The learning theory of this research is focused on the theory of career, which includes two aspects: understanding of self (interests, values, beliefs and others), and understanding of the financial employment market (in addition to compiling interview data from academic advisors and career advisors, students also research information on-line about jobs of their interests that are relevant to financial sectors, and then file them in their personal folders). After compiling data on the understanding of self and market employment, students make tentative career choices for their financial career planning course. The orientation of course design and teaching principles of this research are: (1) problem-solving oriented (collect students' questions concerning personal career planning anonymously, and invite alumni to respond); (2) action-oriented (develop a map of personal career vision, virtual resume and other assignments that apply the career planning strategy of using the end to justify the beginning); (3) cooperative-learning-oriented (the group report at the end of the semester is the integrated focus of individual interviews, which is organized and compiled into a group report); (4) analytical and intellectual inquiry-oriented (two-way communication method is used in each theme-based instruction and organized speech); curriculum design content is focused on cultivating students' core employability. In the content of implemented courses (Peng, 2015a): (1) the focus is on spiritual factors, "Listening and Viewing from a Different Perspective" (conduct discussions, after any designed activities or playing YouTube/Ted Talk videos, to encourage students to listen to their inner voice about their yearnings and make tentative career choices, while listening to the voice from a different perspective/perspective analyses from various lecturers); (2) factors included in the literature review for career planning (interests, values, personality tests, beliefs, role models) are used in the curriculum design for financial specialty-oriented career planning courses; (3) the spirit and method of flipped classroom is stressed (encourage students to view course content Power Point files and supplemental materials Power Point files, under the Class Material Section on the DREAMER http://www.dreamerpengh.com/, prior to asking questions and joining in discussions in the classroom). "The most important work for the teachers is not the lecture, but to motivate students". The classroom and homework assignment design aims to inspire students to participate in static and dynamic classroom activities.

\section{Results}

The research subjects of the first model of this study are 48 freshman students of the Finance Department who elected the "Finance Career Planning" course, and 56 Finance Department freshman students as the subjects of the second model. They are 19-20 years old, and are all freshmen students of the NTUB Finance Department. Before the start of the second-model course, only $70 \%$ of students said they would develop their career in the 
finance related fields, while many students said that they were not familiar with the fields of financial specialties (did not know if the path of banking, insurance, security or other financial fields is suitable for them). At the end of the course, the research found that the course increased the number of students' choosing specialty-oriented careers, where $84 \%$ ( 88 persons) chose jobs in the financial related fields (51 persons in banking, accounting for $49 \%$; 25 persons in security, accounting for $24 \%$; 12 persons in insurance, accounting for $11 \%$ ); 17 persons choose others, accounting for $16 \%$. The survey sample results show that, $65 \%$ (68 persons) are interested in financial fields, $20 \%$ (21 persons) don't know; while 15\% (16 persons) state that they are not interested. The compiled statistics show (Scale Chart 1) that the experimental program model 2 yielded more positive results than model 1, where the overall Mean of the five indicators are significantly improved. This finding is very important to the subsequent promotion of "specialty-oriented career counseling", the participation of career advisor-alumni and the assignment practice of academic advisors.

Table 1. Satisfaction scale differences of the two models of specialty-oriented career counseling course

\begin{tabular}{llllll}
\hline Item & Model & Number & Mean & Standard deviation & t-value/p \\
\hline \multirow{2}{*}{ Richness of the content } & 1 & 48 & 4.09 & 0.84 & $-3.55 / 0.0003^{*}$ \\
& 2 & 56 & 4.58 & 0.69 & $-3.10 / 0.001^{*}$ \\
Clarity of the lecture & 1 & 48 & 3.95 & 0.68 & 0.75 \\
& 2 & 56 & 4.38 & 0.55 & $-4.38 / 0.021^{*}$ \\
Personal gains & 1 & 48 & 3.96 & 0.56 & $-2.49 / 0.008^{*}$ \\
Course relevancy & 2 & 56 & 4.48 & 0.68 & $-2.86 / 0.003^{*}$ \\
Process/activity design & 1 & 48 & 4.17 & 0.59 & $-2.28 / 0.013^{*}$ \\
\hline
\end{tabular}

${ }^{*} p<.05$.

Table 1 shows Mean and Standard deviations of each aspect of the satisfaction scale. On the whole, the Mean of the second model is higher than that of the first model. After conducting t-test on the differences of the two models of "Financial Career Planning" course, t-value of overall satisfaction is -2.28 , reaching the level of significance $(\mathrm{p}<.05)$, showing that the two models are significantly different. The numbers in each aspect: Richness of the content (Model 1: $\mathrm{M}=4.09, \mathrm{SD}=0.84$; Model 2: $\mathrm{M}=4.58, \mathrm{SD}=0.69$ ); Clarity of the lecture (Model 1: $\mathrm{M}=3.95, \mathrm{SD}=0.68$; Model 2: $\mathrm{M}=4.38, \mathrm{SD}=0.75$ ); Personal gains (Model 2: $\mathrm{M}=4.48, \mathrm{SD}=0.56$; Model 1: $\mathrm{M}=3.96, \mathrm{SD}=0.55$ ); Course relevancy (Model 1: $\mathrm{M}=4.17, \mathrm{SD}=0.68$; Model 2: $\mathrm{M}=4.50, \mathrm{SD}=0.5$ ); Process/activity design (Model 1: $\mathrm{M}=4.14, \mathrm{SD}=0.51$; Model 2: $\mathrm{M}=4.48, \mathrm{SD}=0.58$ ); $\mathrm{t}$-values are $-3.55,-3.10$, $-4.38,-2.49,-2.86$ respectively; the statistical results reach significant level $(\mathrm{p}<.05)$, showing significant differences in each aspect of the two models.

In students' open feedback, there are many positive responses concerning the overall planning of this course; for example:

- Thank you for bringing us a course of such rich content, along with a series of activities, this semester! It allows us to explore ourselves in a time of confusion. The lecture is lively, the materials are new. An excellent course!

- Gratitude to the teachers at TYS and alumni for interacting and sharing with us. I feel warm and at ease. Everyone is friendly. Thank you for planning so many activities to cultivate our confidence.

- Every speaker and teacher of this course is seriously invested in the course, wanting to bring us the most substantial knowledge and strength. Therefore, it gives me the strength of persistence. Maybe we are not clear about our direction in the future, but because of this course, I want to know more about myself and to learn from the experience of others. 
- Thank you for guiding us the direction of developing our specialty career! The career planning course in this semester gives me the chance to learn many trivial details to pay attention to in the workplace. TYS lectures and activities are very interesting. The face-to-face interview is nerve-wrecking, but it is a method for me to know more about myself. This is a valuable experience. It is thankful to the help from all the speakers and teachers that I know more about my future direction.

- Before this class, I have never thought about my future. After coming to this class, I start thinking about what do I really want? What am I interested in? At the end of this semester, I am beginning to know more about myself and I can map my future blueprint in my mind.

The qualitative findings gave some support to Ginevra, Pallini, Vecchio, and Nota (2016) emphasize that future orientation and attitudes predict career adaptability which is like subjects' sharing the career planning course gave their strength of persistence and cultivate self-confidence. The findings also put emphasis on that career education assist students' career decisions, which confirmed Fearon, Nachmias, McLaughlin, and Jackson's (2016) study and Maree's (2016) study. Therefore, in higher education offering programs (i.e., the specialty-oriented career planning course or the specialty-oriented career counseling) to increase the college students' specialty career decision making deserves research attention.

\section{Discussion}

This is an experimental program, organized by NTUB and TYS during the 2015-2016 school year, that uses the "Financial Career Planning" of the Finance Department as the experimental course. The findings of this program show that there are significant differences in students' satisfaction concerning the two models of "Financial Specialty-Oriented Career Planning Course". The second model is considered more productive than the first model, when comparing the two promotional models of "specialty-oriented career planning course". The average scores of the five indicators of students' course satisfaction have all reached a significant level (including: the richness of course content, the clarity of lecturer's conveyance, the level of personal learning acquirement, the relevancy of course content to the topic, the design of course process and activities). The biggest differences between the two teaching models of specialty-oriented career planning of the experimental program are: (1) the role modeling of career advisors: inviting alumni to share personal stories on career development, experiences, and to analyze financial specialty development trends; (2) the role modeling of academic advisors: interviewing upper-classmen about their learning plans that are relevant to students' personal learning. In addition, the findings of this research show that in the second model, students' specialty-oriented career choices have increased, in which, students intending to develop their careers in financial related fields were raised from the original $70 \%$ to $84 \%$ by the end of the course (banking $49 \%$, security $24 \%$, insurance $11 \%$ ). Students also mentioned in their feedback that, after finishing the semester-long course, the passion of alumni and teachers encourages the students to start seriously thinking about their future and to make tentative choices. The findings in this study support the ideas proposed by multiple research papers: (1) Career counseling courses/activities are helpful with making career choices (Lam, 2016; Maree, 2016; Shelby, 2010); (2) Role modeling is helpful in college students' career decidedness (Perrone et al., 2002). Comparison results of the two models are also supported: specialty role modeling is helpful with making career choices and having satisfaction with the choices.

Concerning the issues of severe talent-shortage and the mismatch in learning and application in higher education, it is the recommendation of this research that institutions of higher learning should focus on relevant courses in specialty-oriented career planning in each department. It is not only the finance sector that requires specialty talents, they are needed in every sector. "Specialty-oriented career planning counseling" is very important to the development of technical \& vocational education, and it may encourage college students' early career planning in their specialty orientation. College students are malleable and flexible. College freshmen should be encouraged to plan their specialty early in their education with the help of a series of career planning topics to help them understand the development trends of their own specialty fields. The research findings stress that, whether looking at higher education or technical and vocational education, both promotional models of "Specialty-Oriented Career Counseling" have reference values, and that every department should consider strengthening career counseling, with the help of alumni and academic advisors, to improve career specialty employability. Lastly, this research proposes specific recommendations in accordance with the two models of "Specialty-oriented career planning" experimental programs, so that, in this highly competitive and globalized employment market, college students may strengthen their "specialty employability", and improve their "professional employment rate" by applying what they have learned upon graduation, thereby reducing the phenomenon of "the mismatch between learning and application". 
Summarizing the process of implementing both models of courses: Students are encouraged to find a direction in their specialty and specialty learning motivations; Spirituality is incorporated into life education, and speeches that convey enthusiasm for their life's work are provided; Life education should also inspire students to plan their lives, so that students are inspired to think and to explore constantly during the implementation process, and that their reactions and responses are observed and noted; And, Alumni Talks about the four major areas of the financial industry and assignments of interviewing upper-classmen to increase student confidence in learning their specialty are added to the second model. The students gave a positive response to the overall planning of the course in the feedback questionnaire. In the section on notice and recommendation on offering specialty-oriented career planning course, the statistical analysis shows: compared to the first model, all six means of the second model of the experimental program have reached significant levels. The participation of alumni and the interviews of academic advisors activities are highly recommended and very important to the subsequent promotion of "Specialty-Oriented Career Counseling". In the future, lower-classmen's career interviews and specialty-oriented career development course materials from each department may be accumulated with the help of a specially constructed information system. This research recommends that every department should offer a freshman's specialty-oriented career planning course; if offering a separate course is not possible, the curriculum of a specialty-oriented career planning course may be incorporated into basic introductory course/ethic education/service learning courses that combine with the curriculum of moral education, so as to strengthened the cultivation of ethics, etiquette and other positive social habits.

It is important to find a mentor; however, it is not easy to ask a stranger to be a mentor; therefore, there is a need for each department to build a reciprocal upper-lower-classman system to promote the mentoring relationship between alumni and students. This may require un-official, individually-initiated, mentoring systems to provide a network for each student. Students are encouraged to think clearly about what they really want prior to meeting alumni. These alumni are all excellent performers and have the authority to hire; so, instead of wasting this rare opportunity to seek general guidance, take the time to discuss specific opportunities that they may be able to provide, such as work-study, internship and job opportunities. The spirit of "Specialty-oriented career planning" in higher education emphasizes that the direction/goal of specialty career development is as important as dedication and effort. The activities of curriculum design and the arrangement of assignments focus on the importance of mentoring advisors. Students should look for two types of mentoring advisors: (1) career advisor: find a career advisor by contacting alumni of each department; alumni may be student career advisors, who can share personal career development stories to help inspire students' enthusiasm and to share the latest employment development trends in their own fields, as well as advise students on how to prepare for licensing tests, resume-writing, interviewing and internship (work-study); (2) academic advisor: find an academic advisor by implementing the upper-lower classmen system, where junior students may learn about choosing courses to take, arranging for extra-curriculum activities, and understanding the focus of their academic career, so that they are able to schedule their education from freshman year to senior year.

The recommendations of this study: in terms of specialty-oriented career counseling, each department should offer the well-designed, tailor-made, career planning courses, and implement specialty-oriented career counseling measures to better understand individual student's professional interests and personality traits, so as to facilitate more in-depth counseling. In terms of the schools, staff should pay more attention to technical and vocational students' self-reliance and independence within the learning process and should design more career counseling activities and relevant courses. Subsequent research may conduct alumni interviews of, and surveys on other departments and other schools to further explore specialty-oriented career development of technical and vocational students of various departments. The recommendations of this study: in terms of specialty-oriented career counseling activities, two essential interview assignments should be advocated and added into the curriculum of specialty-oriented career counseling courses: (1) career advisors; and (2) academic advisors. Recommendations for subsequent research: (1) future research can also focus on comprehensive qualitative interviews of the same population to have a more in-depth understanding of students' specific changes in responses, attitudes, perceptions or behaviors; (2) after graduation, a follow-up study may be conducted on these samples to observe the success/failure rate in finding finance-related specialty jobs, and to verify that the ratio of applying-what-was-learned has increased; and (3) each department may conduct a survey on specialty indecision, before designing a custom-made specialty-oriented career planning course. 


\section{Reference}

Akbulut, A. Y. (2016). Majoring in information systems an examination of role model influence. Journal of Educational Computing Research, 54(5). https://doi.org/10.1177/0735633115627825

Arnold, J. (1989). Career decidedness and psychological well-being: A two-cohort longitudinal study of undergraduate students and recent graduates. Journal of Occupational Psychology, 62(2), 163-176. https://doi.org/10.1111/j.2044-8325.1989.tb00487.x

Borges, N. J. (2007). Behavioral exploration of career and specialty choice in medical students. The Career Development Quarterly, 55(4), 351-358. https://doi.org/10.1002/j.2161-0045.2007.tb00089.x

Borges, N. J., Manuel, R. S., Duffy, R. D., Fedyna, D., \& Jones, B. J. (2009). Influences on specialty choice for students entering person-oriented and technique-oriented specialties. Medical Teacher, 31(12), 1086-1088. https://doi.org/10.3109/01421590903183787

Brown, S. D., \& Lent, R. W. (2016). Vocational psychology: Agency, equity, and well-being. Annual Review of Psychology, 67, 541-565. https://doi.org/10.1146/annurev-psych-122414-033237

Chason, A. K. (2011). Relationships among Negative Career Thoughts, Profile Elevation, Differentiation, Career Decidedness, and Satisfaction with Choice (Unpublished doctoral dissertation). Florida State University, Tallahassee, Florida.

Cui, J., Wang, Z., \& Peng, H. (2015). Action Research on Specialty-Oriented Counseling and the Construction of Alumni Career Information-Using the Finance Department of NTUB as an Example. Chang Jung Christian University Multiple-Aspect Teaching Improvement Seminar Paper.

Davis, R. C., \& Horne, A. M. (1986). The Effect of Small-Group Counseling and a Career Course on Career Decidedness and Maturity. Vocational Guidance Quarterly, 34(4), 255-262. https://doi.org/10.1002/j.2164-585X.1986.tb00861.x

Fearon, C., Nachmias, S., McLaughlin, H., \& Jackson, S. (2016). Personal values, social capital, and higher education student career decidedness: A new "protean"-informed model. Studies in Higher Education, 41, 1-23. https://doi.org/10.1080/03075079.2016.1162781

Ginevra, M. C., Pallini, S., Vecchio, G. M., \& Nota, L. (2016). Future orientation and attitudes mediate career adaptability and decidedness. Journal of Vocational Behavior, 95, 102-110. https://doi.org/10.1016/j.jvb.2016.08.003

Hadadgar, A., Yousefi, A., Sabouri, M., \& Richard, G. (2009). Psychometric properties of a Persian version of the specialty indecision scale: A preliminary study. Iranian Journal of Medical Education, 8(2), 229-237.

Huang, Y. (2016). The study on the relationships among differentiation of self, career coping strategies and career decisions of college students (Master's degree thesis). Graduate Institute of Educational Psychology and Counseling, Tamkang University, Taipei City.

Jin, S. (2011). Career Consultation and Counseling. Taipei: Tung Hua Book Co., Ltd.

Jin, S., Lin, C., \& Tien, H. (1989). The Career Development of Chinese College Students in Taiwan. Journal of Educational Psychology, 22, 167-190.

Jin, S., \& Sheu, H. (2010). The effects of career intervention strategies for improving cognitive complexity and career self-efficacy of junior-high students. Journal of Educational Psychology, 35(2).

Lam, M. (2016). Effects of a career course on students' career decision-making self-efficacy, indecision and difficulties (Unpublished doctoral dissertation). University of Nottingham Malaysia Campus.

Lent, R. W., Ezeofor, I., Morrison, M. A., Penn, L. T., \& Ireland, G. W. (2016). Applying the social cognitive model of career self-management to career exploration and decision-making. Journal of Vocational Behavior, 93, 47-57. https://doi.org/10.1016/j.jvb.2015.12.007

Lepper, C. (2016). Advising undecided college students (working paper).

Liang, S. (2016). A Study on the Influence of College Students' Working Values, Personal and Environmental Adaptability on Career Orientation. Cultural and Educational Information, 11, 138-140.

Lin, C. (2016). NTUB Assessment Report (Unpublished). 
Lin, C., Lin, Y., \& Peng, H. (2016). Youth Career Development Center Project Closure Report-"Career Counseling Education" Course Model Experimental Program (II) of the National Taipei University of Business and Taipei Youth Salon - Using the Finance Department of NTUB as an Example (Unpublished).

Lin, Y. (2016). NTUB Finance Department Assessment Report (Unpublished).

Lin, Y., \& Peng, H. (2015). Youth Career Development Center Project Closure Report-"Career Counseling Education" Course Model Experimental Program (I) of the National Taipei University of Business and Taipei Youth Salon-Using the Finance Department of NTUB as an Example (Unpublished).

Manpower Group Global Employment Talent Shortfall Survey. (2016). Manpower Group. Retrieved November 1, 2016, from http://www.manpower.com.tw/

Mao, C., Hsu Y., \& Fang T. (2016). Mediating Effect of Career Decision Self-Efficacy on the Relationship between Parental Support and Indecision in Taiwan. Journal of Career Development. https://doi.org/10.1177/0894845316663319

Maree, J. G. (2016). Career Construction As a Way of Resolving Career Indecision. South African Journal of Higher Education, 30(3), 170-192. https://doi.org/10.20853/30-3-665

Peña-Calvo, J. V., Inda-Caro, M., Rodríguez-Menéndez, C., \& Fernández-García, C. M. (2016). Perceived supports and barriers for career development for second-year STEM students. Journal of Engineering Education, 105(2016), 341-365. https://doi.org/10.1002/jee.20115

Peng, H. (2016). Action Research on Specialty-Oriented Career Planning Courses for Financial College Students-Using the Finance Department of NTUB as an Example. The Journal of Open and E-learning, 6, $147-172$.

Peng, H. (2015a). Infusing positive psychology with spirituality in a strength-based group career counseling to evaluate university students' state anxiety. International Journal of Psychology Studies, 7(1), 75-84. https://doi.org/10.5539/ijps.v7n1p75

Peng, H. (2015b). New News-An Analysis of Financial Career Planning Courses, On the Importance of "Specialty-Orientation Career Counseling" in Higher Education. NTUB E-Periodical, 2(1).

Peng, H., \& Huang, S. (2007). Mental Health and Career Development. NTUB Counseling Center Journal.

Perrone, K. M., Zanardelli, G., Worthington, JR. E. L., \& Chartrand, J. M. (2002). Role model influence on the career decidedness of college students. College Student Journal, 36(1), 109-112.

Restubog, S. L. D., Florentino, A. R., \& Garcia, P. R. J. M. (2010). The mediating roles of career self-efficacy and career decidedness in the relationship between contextual support and persistence. Journal of Vocational Behavior, 77(2), 186-195. https://doi.org/10.1016/j.jvb.2010.06.005

Richard, G. V., Savickas, M. L., Early, L., Calli, J., Carissa, Englert, C. A., \& Bono, J. (2007). Manual for the specialty indecision scale. Washington DC: Association of American Medical Colleges.

Sajjad, M., Khan, R. A., \& Qayyum, S. (2016). Choice of Specialty Careers among Final Year MBBS Students. Journal of Islamic International Medical College, 11(2), 81-84.

Sandberg, S. (2013). Women, work, and the will to lead. Random House.

Savickas, M. L., Alexander, D. E., Jonas, A. P., \& Wolf F. M. (1986). Difficulties experienced by medical students in choosing a specialty. Academic Medicine, 61(6), 467-469. https://doi.org/10.1097/00001888-198606000-00005

Savickas, M. L., Alexander, D. E., Osipow, S. H., \& Wolf, F. M. (1985). Measuring specialty indecision among

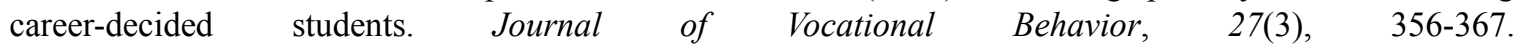
https://doi.org/10.1016/0001-8791(85)90042-9

Shelby, T. L. (2010). Impact of a standardized cognitive information processing intervention on the career decision state of at-risk youth (Unpublished doctoral dissertation). Florida State University, Tallahassee, Florida.

Shih, S. (2010). A Study on the Relationship between Self-concept and the Degree of Career Decision of the College Students in Taiwan (Master's degree thesis). National Taipei University of Technology, Taipei City.

Steele, G. E. (2016). Advising Undecided College Students. 
van Tuijl, C., \& van der Molen, J. H. W. (2016). Study choice and career development in STEM fields: An overview and integration of the research. International Journal of Technology and Design Education, 26(2), 159-183. https://doi.org/10.1007/s10798-015-9308-1

Weng, K., \& Chang, F. (2011). Mismatch between Education and Work: School to Work Transition after Higher Education Expansion. Review of Social Sciences, 5(1), 1-38.

Zachar, P., \& Leong, F. T. L. (1997). General versus specific predictors of specialty choice in psychology: Holland codes and theoretical orientations. Journal of Career Assessment, 5(3), 333-341. https://doi.org/10.1177/106907279700500306

\section{Copyrights}

Copyright for this article is retained by the author(s), with first publication rights granted to the journal.

This is an open-access article distributed under the terms and conditions of the Creative Commons Attribution license (http://creativecommons.org/licenses/by/4.0/). 